\title{
Sobre terminología errónea en publicaciones entomológicas
}

\author{
Luko Hilje \\ Departamento de Agricultura y Agroforestería, Centro Agronómico Tropical de Investigación y Enseñanza (CATIE), \\ Turrialba, Costa Rica; luko@ice.co.cr
}

Recibido 26-I-2011. Corregido 10-II-2011. Aceptado 03-III-2011.

\begin{abstract}
On some misused terms in entomological publications. A glossary is presented, despite being a non-exhaustive one, which includes a little more than one hundred terms frequently misused in entomological publications. They are organized in accordance to their degree of acceptance by the Real Academia Española. Each one is accompanied by its correct alternative (sometimes with a brief justification of the suggested term), and its proper use is illustrated with an example. Moreover, in addition to idiomatic mistakes themselves, a brief list of rather common conceptual mistakes is included, which correct use is explained. Rev. Biol. Trop. 59 (3): 999-1006. Epub 2011 September 01.
\end{abstract}

Key words: entomology, terminology, concepts, language, Spanish.

Con esta recopilación, que de ninguna manera es exhaustiva, se pretende llamar la atención acerca del empleo incorrecto de numerosos términos en publicaciones entomológicas, y la necesidad de enmendarlos, para evitar la perpetuación de su inadecuada utilización.

Dichos términos frecuentemente son desatendidos por muchos autores, e incluso a veces por revisores y editores de artículos, lamentablemente. El autor, quien ha incurrido en la mayoría de ellos, los ha recopilado de manera paulatina para ayudar especialmente a los estudiantes en su correcta utilización. Este es un imperativo no solo por razones de precisión en la comunicación científica, sino también por respeto a la lengua española que, aunque no es tan ágil y flexible como la inglesa para crear rápidamente términos -sobre todo aquellos asociados con el vertiginoso desarrollo de la técnica y la tecnología-, tiene una extraordinaria riqueza de vocablos, también útiles en las disciplinas científicas y técnicas, muchas veces desconocidos para nosotros.
El presente texto está dividido según la naturaleza de los errores, a saber: idiomáticos o de concepto. Los errores del primer tipo corresponden generalmente a la traducción literal de términos de otros idiomas, o a palabras empleadas de manera equivocada; algunos son correctos en otros contextos, pero no en el de interés nuestro. Estos se clasificaron en tres secciones, dependiendo del grado de aceptación de la alternativa ofrecida por nosotros, por parte de la Real Academia Española (RAE), lo cual hemos verificado tanto en su diccionario oficial (DRAE 2001) como en su portal de internet (http://buscon.rae.es/draeI).

Cabe indicar que, en cada sección, los términos están organizados en orden alfabético. Al lado de cada uno aparece su origen en el idioma inglés (si se trata de un neologismo o de un barbarismo), seguido por la opción correcta (a veces con una breve justificación del término sugerido), cuyo uso se ilustra con un ejemplo, en cada caso, para facilitar su comprensión. 


\section{TÉRMINOS ERRÓNEOS}

Agroquímicos (agrochemicals): productos agroquímicos. Es un adjetivo y no un sustantivo. Ej. Los plaguicidas, fertilizantes, reguladores de crecimiento y defoliantes son productos agroquímicos.

Agrotóxico (agrotoxic): ver agroquímicos .

Alimenticio: alimentario. Ej. Los depredadores y los parasitoides representan al eslabón de los carnívoros en las cadenas alimentarias.

Anti-alimentario (anti-feedant): fagodisuasivo. Ej. Dichas sustancias vegetales tienen un efecto fagodisuasivo para la larva.

Arsenal (arsenal): repertorio. Ej. El repertorio de métodos de combate es amplio.

Asunción (assumption): supuesto. Ej. El modelo matemático se basa en el supuesto de que no hay inmigración de individuos en dicha población de insectos.

Bacterial (bacterial): bacteriano. Ej. El insecticida bacteriano fue más eficaz que los convencionales.

Bafles (baffles): aspas. Ej. La trampa luminosa para capturar insectos tiene dos aspas.

Biocontrol (biocontrol): combate biológico. Ej. El combate biológico tiene varias ventajas sobre los métodos convencionales.

Claspers (claspers): garfio. Ej. En el momento de la cópula, el macho sostiene a la hembra con los garfios asociados con el falo o pene.

Colectar (to collect): recolectar. Ej. Las muestras se recolectaron temprano, por la mañana.

Color claro: tonalidad clara. No existe un color denominado claro. Ej. El tórax es de tonalidad amarillo claro.

Comensal (commensal): domiciliario. Ej. Las cucarachas son insectos domiciliarios.

Competición (competition): competencia. Aunque es válida, es preferible usar el término competencia. Ej. La competencia entre ambas especies fue más aguda.

Contagioso (contagious): agregado. Ej. Tanto las ninfas como los adultos mostraron un patrón de distribución espacial agregado.

Contaje: conteo, recuento. Ej. En la primera muestra, los recuentos de larvas fueron altos.

Crawler: gateadora. Ej. Recién nacida, la ninfa gateadora se establece cerca de donde emergió.

Crochets: corchetes, ganchillos. Ej. Las patas falsas (espuripedios) de las larvas de lepidópteros se caracterizan por poseer abundantes corchetes.

Cultural (cultural): agrícola. Ej. Las prácticas agrícolas son importantes dentro de la estrategia del manejo integrado de plagas.

Diabrótica: ejemplo común del error de tildar nombres científicos, lo cual no debe hacerse nunca. Cabe indicar que todos los nombres deben pronunciarse como si fueran palabras graves, por lo que en este caso sería Diabrotica.

Deterrente (deterrent): disuasivo. Ej. Las sustancias disuasivas impiden que el insecto adulto consuma las hojas de dicha planta.

Disectar (to dissect): disecar. Ej. El insecto debe ser disecado para observar bien sus tráqueas.

Dispersión (dispersion): distribución espacial. Ej. Inicialmente, los adultos mostraron una distribución espacial aleatoria.

Dormancia (dormancy): latencia. Ej. Cuando las condiciones climáticas son inadecuadas, los insectos entran en latencia.

Eclosionar: acción de abrirse. Ej. El huevo eclosionó / El capullo eclosionó. No es la larva quien eclosiona del huevo, ni la mariposa del capullo; ellas emergen de esos estadios previos.

Efectividad (effectiveness): eficacia o eficiencia. Ej. El insecticida fue eficaz / El muestreador fue eficiente. Sí es válido en el sentido de alcanzar el efecto esperado (Ej. El insecto respondió al estímulo visual, efectivamente). 
Ensayo: experimento. Ej. El experimento se estableció durante la estación seca.

Especimen: espécimen. Ej. El espécimen fue depositado en una colección de referencia.

Estarvación (starvation): inanición. Ej. Las larvas murieron de inanición.

Filosofía (philosophy): noción. Ej. El manejo integrado de plagas es una noción relativamente nueva.

Genitalia: órganos genitales. Ej. En las formas inmaduras de esta especie de dípteros no es posible distinguir los futuros órganos genitales.

Hibridizar (to hybridize): hibridar. Ej. Es factible hibridar ambas especies de mariposas.

Hospedero: hospedante. Entre los términos hospedero, huésped y hospedante son frecuentes las confusiones en cuanto a quién recibe a quién, por lo que es mejor usar la voz activa de hospedante, como el que alberga, nutre, etc. Ej. Este homóptero, vector, actúa como hospedante de ese tipo de virus.

Huésped: ver hospedero.

Huevecillo: huevo. Ej. Los huevos de los ácaros son diminutos.

Invierno: estación lluviosa. Ver verano.

Lucir (to look): parecer. Ej. El huevo de esta especie de mosca parece diferente del de esta otra, a pesar de la afinidad taxonómica de ambas.

Lumínica (luminic): luminosa. Ej. Se utilizó una trampa luminosa para capturar los insectos.

Llave (key): clave. Ej. Clave para familias de Hymenoptera de Panamá.

Maleza: arvense. Puesto que ninguna planta es nociva per se, no cabe calificarla como tal, por lo que es preferible usar el término alternativo, proveniente del latín arva, que significa campo cultivado. Ej. Numerosas especies de parasitoides se asocian con arvenses, de las cuales toman su néctar.
Menú: ver arsenal.

Microbial (microbial): microbiano. Ej. Los insecticidas microbianos son compatibles con el uso de parasitoides.

Nutriente (nutrient): nutrimento. Ej. Se agregaron nutrimentos a las plantas.

No publicado (unpublished): inédito. Ej. En el laboratorio, el ciclo de vida del insecto demora cerca de 45 días (Ramírez 2007, inédito).

Ocurrencia (occurrence): presencia. Ej. La presencia estacional de dicho coleóptero fue muy afectada por la precipitación.

Ocurrir (occur): aparecer. Ej. Las especies de libélulas aparecen en hábitats acuáticos.

Overlapo (overlap): traslapo. Ej. No se detectó traslapo alguno entre la distribución geográfica de ambas especies de mariposas.

Papel (paper): artículo científico. Ej. Durante el decenio anterior, se publicaron 296 artículos científicos sobre entomología.

Pelet (pellet): perdigón. Ej. Dicho insecticida normalmente se formula como perdigones.

Peletizado (pelletized): aperdigonado. Ej. En tal caso es recomendable utilizar cebos aperdigonados.

Pegante: adhesiva. Ej. Las trampas amarillas adhesivas son muy útiles para capturar áfidos.

Peste (pest): plaga. Se acepta peste, pero con otras acepciones, sin aludir a organismos dañinos. Ej. Muchas especies de insectos herbívoros se pueden convertir en plagas fácilmente.

Pila génica (gene pool): acervo genético. Ej. Los genes de resistencia a dicho insecticida quedaron incorporados al acervo de la población.

Pitfall (pitfall trap): trampa de foso (en el suelo). Ej. Las trampas de foso son eficaces para capturar insectos que deambulan sobre el suelo.

Plantas voluntarias (volunteer plants): plantas residuales, que nacen después de la cosecha de 
un cultivo. Ej. Las plantas residuales favorecieron la permanencia del insecto en el campo, una vez cosechadas las parcelas.

Plato petri (petri dish): caja de Petri, inventada en 1887 por el alemán Richard Julius Petri. Ej. Para su observación, las larvas se colocaron en cajas de Petri, junto con follaje de la planta.

Plotear (to plot): graficar. Ej. Los datos fueron graficados apenas concluyó el experimento.

Pluma (plume): rastro. Ej. El rastro de la feromona femenina es detectado por los machos, durante su vuelo.

Pool (pool): ver pila génica.

Practicalidad (practicality): funcionalidad. $\mathrm{Ej}$. El método de combate fue rápidamente adoptado por los agricultores, debido a su funcionalidad.

Predata (predate): depreda. Ej. El coccinélido depredó a los áfidos en 20 minutos.

Predator (predator): depredador. Ej. La reacción del depredador ante la presencia de la presa fue inmediata.

Químicos (chemicals): ver agroquímicos.

Randomizar (to randomize): ver azarizar.

Rango (range): ámbito, amplitud. Ej. El ámbito de distribución de esa especie de abejas comprende toda Mesoamérica. Actualmente se acepta, en estadística, como la amplitud de la variación de un fenómeno entre un límite menor y uno mayor. Ej. El ámbito de valores de la longitud de la proboscis fue estrecho.

Razón (ratio): proporción. Ej. En dicha especie, la proporción de sexos está sesgada a favor de las hembras.

Resiliencia (resilience): elasticidad. Ej. Este tipo de comunidades biológicas tienen gran elasticidad, por lo que pueden reponerse relativamente rápido de perturbaciones.

Responsable de (responsible for): causa. Ej. La larva es causante del daño observado en ese tipo de fruto.
Ripario (riparian): ribereño. Ej. Durante la estación seca es común que las chicharras se congreguen en los bosques ribereños.

Salvaje (wild): silvestre. Ej. En la vegetación silvestre es común hallar abundante especies de insectos herbivoros y de parasitoides.

Sinergístico (synergistic): sinérgico. Ej. La mezcla de ambos insecticidas tuvo un efecto sinérgico sobre dicha plaga. Por cierto, el término correcto es sinergia y no sinergismo.

Sobrevivencia: supervivencia. Ej. Ese tipo de adaptaciones es lo que permite la supervivencia de las larvas, a pesar de la alta temperatura.

Survey (survey): censo, encuesta. Ej. El censo de especies fue exitoso / La encuesta fue fundamental para el diagnóstico oportuno de los problemas que enfrenta el cultivo.

Territorialismo (territorialism): territorialidad. Ej. En las libélulas es frecuente observar el fenómeno de la territorialidad.

Transecto (transect): trayecto. Ej. El muestreo se efectuó estableciendo cuatro trayectos a lo largo de la parcela.

Traslape: ver overlapo.

Verano: estación seca. En las regiones tropicales no existen las cuatro estaciones típicas de las regiones templadas. De hecho, más bien, en América Central la estación seca se presenta durante los meses de invierno en al hemisferio norte. Ej. Muchas especies de insectos alcanzan poblaciones altas durante la estación seca.

Vegetales (vegetables): hortalizas. Ej. En general, en las hortalizas se utiliza mucho plaguicida.

Vial (vial): frasco. Ej. Las muestras se depositaron en un frasco pequeño.

Zigoto (zygote): cigoto. Ej. El cigoto es el resultado de la fusión del gameto masculino con el femenino. 


\section{TÉRMINOS SIN ALTERNATIVA ACEPTADA AÚN}

En esta sección aparecen dos tipos de términos. Unos son utilizados de manera frecuente y normal en publicaciones entomológicas, aunque no han sido aceptados por la Real Academia Española. Los otros son utilizados de manera incorrecta -como se les consigna en la lista-, pero la opción aquí ofrecida no tiene aceptación aún. Por tanto, en teoría, tampoco sería correcto emplear la opción sugerida, aunque por analogía con palabras emparentadas con cada una, o por lógica, debieran ser adoptadas en el futuro, en la medida en que su empleo frecuente las legitime, como ha sucedido recientemente con palabras como bit, byte, chip, Internet, software, spray, etc.

Aislados (isolates): aislamientos (alude a la separación de un organismo patogénico de su hospedante y su cultivo o crianza en un medio nutritivo). Ej. Se cuenta con ocho aislamientos de hongos entomopatogénicos.

Alopátrica (alopatric): alopátrida (tiene sentido, por analogía con apátrida). Ej. Ambas especies de saltamontes son alopátridas.

Azarizar: aleatorizar (o sortear). Ej. En el campo, los tratamientos se aleatorizaron dentro de cada bloque.

Bioensayo (bioassay): ver ensayo. Aunque podría utilizarse el término bioexperimento (pero todos los experimentos biológicos lo serían, sensu stricto) u otro análogo, el término bioensayo tiene una acepción muy particular, pues se refiere a la determinación de la potencia de una sustancia (plaguicida, medicamento, etc.) cuando se evalúa sobre un organismo vivo.

Bioracionales (biorationals): bioinsumos. Ej. En los nuevos enfoques de producción agrícola, sería pertinente la utilización de bioinsumos.

Canopia (canopy): dosel. Ej. Algunos miembros de esa familia de mariposas normalmente habitan el dosel del bosque.
Control (control): combate (en español, control significa comprobación, inspección, fiscalización o intervención). Ej. El combate de la plaga fue difícil, debido a sus hábitos.

Cultivar: variedad cultivada (una variedad es un grupo de individuos que difieren genéticamente de otro grupo perteneciente a la misma especie). Ej. Se cuenta con dos cultivares de tomate resistentes a dicha plaga.

Encapsulación (encapsulation): encapsulamiento. Ej. Las células del hospedante lograron el encapsulamiento del huevo del parasitoide.

Fitofagia: sinónimo de herbivorismo. Ej. La fitofagia es la regla en el orden Saltatoria.

Fitoprotección: equivalente a protección vegetal, que es la rama que aborda el estudio y manejo de las plagas agrícolas y forestales. Ej. La entomología es una de las principales disciplinas de la fitoprotección.

Herbivorismo (herbivory): Ej. El herbivorismo es un hábito alimentario muy común en insectos.

Manejo (management): en español, manejo significa gobernar o dirigir un negocio. Ej. El manejo integrado de plagas representa el principal paradigma en el campo de la protección vegetal.

Monitorear (to monitor): en español no existe un término que incluya, a la vez, las ideas de evaluación instantánea y de seguimiento en el tiempo; puesto que monitor sí existe, posiblemente será acogida en el futuro. Ej. Para un manejo adecuado de dicha plaga es indispensable monitorear su población mediante trampas de feromonas.

Oviparismo (oviparism): oviparidad. Ej. La oviparidad es el método de reproducción más común entre los insectos.

Parasitoidizar: parasitar (aunque hay diferencias funcionales entre un parasitoide y un parásito, por el contexto en que se emplee, el término parasitar sería autoexplicativo, y más 
simple). Ej. El microhimenóptero parasitó a la larva de mariposa.

Multivoltino (multivoltine): policíclico. Ej. Esa especie de avispas es policíclica, pues tiene varias generaciones por año.

Probit (probit). Término de la teoría de probabilidades y la estadística que, entre otros, se aplica en modelos de la regresión en los que las respuestas esperadas son de carácter binario. Ej. La línea log-probit aporta una idea cabal de la relación entre la dosis del insecticida y la mortalidad de las larvas.

Pupar (pupate): empupar. Ej. La larva empupó en el suelo.

Retroalimentación (feedback).Ej.En la estructura de un agroecosistema es posible identificar numerosos circuitos de retroalimentación.

Simpátrica (sympatric): simpátrida. Ej. Ambas especies de moscas son simpátridas.

Univoltino (univoltine): monocíclico. Ej. Esa especie de coleóptero es monocíclica, pues tiene una sola generación por año.

Virótico: virulífero (portador de virus). Ej. El número inicial de individuos virulíferos es determinante del curso de la epidemia.

Viviparismo (viviparism): viviparidad. Ej. La viviparidad es un método de reproducción poco frecuente entre los insectos.

Zeitgeber: no existe una traducción de este término alemán, tan importante para describir los fenómenos asociados con el reloj biológico de los organismos. Se trata de algo así como un "diario-sensor" o "sincronizador ambiental". Ej. La menor cantidad de horas de luz, diariamente, es lo que actúa como el zeitgeber para dicho insecto.

\section{TÉRMINOS AHORA ACEPTADOS}

En esta sección aparecen algunos términos cuyo uso se consideraba incorrecto hasta hace pocos años, por lo que los habíamos recopilado, pero ya han sido aceptados por la Real
Academia Española. Han permanecido en este artículo por si el lector tuviera dudas acerca del uso de dichas palabras. En algunos casos hemos consignado al lado del respectivo término la opción que ya existía en español, y que sigue siendo válida.

Altamente (highly): muy. Ej. El depredador fue muy (altamente) eficiente.

Alternativa (alternative): opción. Ej. Existen cuatro opciones (alternativas) para el manejo de esta plaga.

Café: pardo, marrón. Ej. La palomilla tiene alas pardas (marrón, café).

Implementar (to implement): operacionalizar. Ej. El programa fue operacionalizado (implementado) en el campo.

Naranja: anaranjado. Ej. La mariposa tiene alas anaranjado (naranja) intenso.

Obsoleto (obsolete): anacrónico. Ej. Dicho concepto es anacrónico (obsoleto), a la luz de los nuevos descubrimientos en ese campo.

Polución (pollution): contaminación. Ej. Estas larvas son indicadoras de altos niveles de contaminación (polución) en los ríos.

Pesticida (pesticide): plaguicida. Ej. Los plaguicidas (pesticidas) han sido el método más común para el combate de plagas agrícolas.

Predador (predator): depredador. Ej. El depredador (predador) consumió a su presa de inmediato.

Progenie (progeny). Término ambivalente, que puede referirse tanto a la prole o descendencia, como a los padres. Ejs. La prole (progenie) de esta pareja de mariposas fue muy numerosa I Para buscar árboles resistentes a dicha plaga, se recolectaron 30 padres (progenies) en varios países tropicales.

Rata (rate): tasa. Ej. La tasa (rata) de crecimiento poblacional mostró un incremento solamente al principio de la temporada. 
Reportar (report): informar. Ej. El especialista informó sobre la presencia de una nueva especie de mariposa en dicha localidad.

Spray (spray): aerosol, atomizador. Ej. El aerosol (spray) fue suficientemente fino para penetrar en tan denso follaje / Se utilizó un atomizador (spray) manual.

Surfactante (surfactant): agente tensoactivo. Ej. El insecticida aumenta su eficacia si se le agrega un agente tensoactivo (surfactante) adecuado.

\section{ERRORES DE CONCEPTO}

Estos términos corresponden a conceptos biológicos y ecológicos, así como a ciertas normas taxonómicas, que con frecuencia se emplean de manera incorrecta. Por tanto, se presenta cada término acompañado con una explicación acerca de su significado adecuado.

Competencia: Algunos textos sugieren o indican que hay competencia entre un herbívoro y su depredador o parasitoide, lo cual es inexacto. Puede ocurrir solo cuando un recurso (algo que satisface una necesidad, como la luz, espacio, alimento, etc.) es escaso y compartido por individuos de una misma especie (intraespecífica) o de especies diferentes (interespecífica).

Depredador de frutos: Es mejor reservar el término depredador para el acto de matar y consumir a otro animal, es decir, para animales carnívoros. En este caso, es mejor utilizar el frugívoro (o herbívoro o fitófago, si se trata de otra estructura de la planta).

Dinámica de población: De este concepto se abusa mucho y generalmente se le equipara con el simple recuento de la abundancia de una especie mediante trampas de luz o feromonas. En realidad, el término alude a que ninguna población es estática en su densidad (es afectada por las tasas de natalidad, inmigración, mortalidad y emigración) ni en su composición genética (riqueza y frecuencias de genes).
Ecología: Comúnmente se dice que "la ecología de un lugar ha sido muy alterada”. Los ecosistemas pueden ser alterados, pero no la ecología, que es una ciencia. Esto sería como decir que la sociología (y no la cultura) de una comunidad indígena se ha distorsionado debido a influencias exógenas. Por tanto, ese uso es inapropiado.

Estadio: En español, se refiere a una etapa o fase de un proceso de transformación, como lo es la metamorfosis. Por tanto, hay estadios de huevo, larva, pupa, ninfa o adulto, según el tipo de metarmorfosis. La confusión surge cuando hay que dividir los estadios de larva o ninfa en subestadios, para lo cual se utiliza la denominación instar. En esto aún no hay consenso entre autores.

Erradicación: Aunque para insectos recién ingresados a una región, es posible la erradicación, éste no es el propósito del manejo de insectos plaga. Por tanto, es incorrecto señalar que mediante varias tácticas de manejo integrado de plagas se intentó erradicar a un insecto ya establecido o nativo de una región.

et al.: Estas son las abreviaturas de et álii (debería escribirse et ál.) que significa " $y$ otros". Se utiliza por simplicidad, al hacer citas en el texto, cuando el artículo tiene más de dos autores, y siempre en letra cursiva o bastardilla. Por ejemplo, se escribe Saunders et ál. (1983), en vez de Saunders, King y Vargas (1983). Nótese que la partícula et no lleva punto.

Extinción: Se ha documentado que muchas especies de organismos se han extinguido y que muchas otras corren el riesgo de hacerlo. No obstante, en ecología este término frecuentemente se utiliza para las extinciones locales, es decir, cuando una especie desaparece de cierta zona.

Fluctuación: Este término, al igual que oscilación, implica la existencia de crecimiento y disminución alternativamente, con mayor o menor regularidad. Por tanto, no son sinónimos de la simple variación en las densidades de una población. 
Gennadius: Este es un ejemplo del descuido existente en cuanto al uso del nombre de los autores de nombres científicos. Por ejemplo, P. Gennadius es el autor del nombre de la mosca blanca Bemisia tabaci (Gennadius). Su nombre se escribe completo, y no Genn. ni G., como aparece incluso en publicaciones formales; la abreviatura se admite para autores muy conocidos, como Linneo (L.). Además, se debe escribir entre paréntesis porque cambió el nombre original de la especie, que era Aleyrodes tabaci Gennadius. En suma, el uso de paréntesis no es caprichoso, sino que obedece a reglas de nomenclatura aprobadas internacionalmente.

Nicho ecológico: El término nicho (lugar donde se coloca a un santo en las paredes de una iglesia o a un difunto en el cementerio), ha originado gran tergiversación y su frecuente empleo erróneo. El nicho no es el lugar (hábitat) donde vive un organismo, sino lo que hace; es decir, su funcionalidad o papel específico en el ecosistema del cual forma parte (hábitos alimentarios, ubicación trófica, reproducción, habilidad competitiva, tolerancia al clima, etc.).

nr.: Cuando no se está totalmente seguro de la identidad de una especie, pero se presume que pertenece a cierta especie, se interpone la partícula ca. entre los nombres genérico y específico (por ejemplo, Platypus ca. dolabrata). Dicha partícula latina es la abreviatura de circa (cercana a). Es incorrecto usar nr., que es una abreviatura de "near", que en inglés significa "cerca".

Parásito: Con frecuencia se usa el término como equivalente de parasitoide. Aunque comparten algunas características, la principal diferencia es que el parasitoide mata al hospedante siempre, mientras que el parásito casi nunca lo hace.

Regulación: De este término se abusa mucho. En sentido estricto, la regulación de una población puede ser ejercida solamente por factores bióticos. Por ejemplo, la temperatura o la humedad pueden afectar a una población de insectos, pero no regularla. Regular significa que la densidad del factor de mortalidad (por ejemplo, enemigos naturales) es afectada recíprocamente por la densidad de su hospedante o presa (lo cual no puede suceder con los factores abióticos).

sps.: Si se desconoce la identidad de cierta especie, se agrega la partícula sp. al nombre del género (por ejemplo, Neosilba sp.) y no se subraya ni se escribe con bastardilla. La partícula spp., y no sps., es la forma plural, y se usa para un grupo de especies congéneres (por ejemplo, Phyllophaga spp.).

\section{AGRADECIMIENTOS}

Dedico este artículo a la memoria del Dr. Luis Fournier Origgi, quien como profesor me estimuló en el empleo correcto de la lengua española en el campo de las ciencias biológicas. Asimismo, agradezco a los filólogos Fernando Diez Losada (diario La Nación, Costa Rica) y Carlos Francisco Monge (Escuela de Literatura y Ciencias del Lenguaje, Universidad Nacional, Costa Rica) la revisión del documento. No obstante, el contenido es responsabilidad exclusiva del autor.

\section{RESUMEN}

Este artículo consiste en un glosario, aunque no exhaustivo, de un poco más de cien términos con cierta frecuencia empleados de manera incorrecta en publicaciones entomológicas. Éstos se clasifican según el grado de aceptación por parte de la Real Academia Española. Cada uno es acompañado por la opción correcta (a veces con una breve justificación del término sugerido), cuyo uso se ilustra con un ejemplo en cada caso. Asimismo, aparte de estos errores propiamente idiomáticos, se incluye una breve lista de ciertos errores de concepto, también comunes, cuyo correcto uso es explicado.

Palabras clave: entomología, terminología, conceptos, lenguaje, español. 